\title{
A SOCIEDADE DA INFORMAÇÃO SEUS REFLEXOS NA OBJETIFICAÇÃO DA MULHER
}

\section{THE INFORMATION SOCIETY ITS REFLECTIONS ON THE OBJECTION OF WOMEN}

\author{
${ }^{1}$ Schmitz, Gabriele Ana Paula Danielli \\ ${ }^{2}$ Tramontina, Robison
}

\section{RESUMO}

Esse trabalho aborda a objetificação da mulher e sua relação com o desenvolvimento da sociedade da informação. A questão que orienta essa investigação é: qual a relação da objetificação com o desenvolvimento da sociedade da informação? Para responder a esta indagação observou-se a seguinte trajetória: abordou-se a sociedade da informação; a objetificação da mulher, a fim de demonstrar seu conceito e situações em que é empregado; e por último a objetificação da mulher, com o intuito de responder qual é a sua relação com a sociedade da informação. O método de pesquisa é o dedutivo.

Palavras-chave: Sociedade da informação. Objetificação. Mulher.

\section{ABSTRACT}

This paper addresses the objectification of women and its relation to the development of the information society. The choice of theme motivates by its contemporary, especially the expansion of the media, which directly influence the objectification of women. The question that guides this research is: what is the relationship of objectification with the development of the information society? To answer this question argumentative split was based on the following path: first addressed the information society ,; following was made an analysis of women's objectification in order to demonstrate its concept and situations in which it is employed; Finally we analyzed the objectification of women, in order to answer what is your relationship to the information society. The research method to be adopted will be the deductive method and methodology as the literature.

Keywords: Information society. Objectification. Woman.

\footnotetext{
${ }^{1}$ Mestre em Direito pela Universidade do Oeste de Santa Catarina (UNOESC), Joaçaba, Santa Catarina, Brasil. Email: gabriele27264@gmail.com

${ }^{2}$ Doutor em Filosofia pela Pontifícia Universidade Católica do Rio Grande do Sul. Professor do Programa de Mestrado em Direitos Fundamentais da Universidade do Oeste de Santa Catarina (UNOESC), Joaçaba, Santa Catarina, Brasil. Email: robison.tramontina@unoesc.edu.br
} 


\section{INTRODUÇÃO}

As discussões em torno do tema da objetificação da mulher não são tão recorrentes nos espaços públicos, pois o maior enfoque ainda reside na violência sexual contra as mulheres. Entretanto, diante da crescente importância da questão referente à objetificação do corpo da mulher, o assunto tem ganhado espaço.

Para tratar do tema, optou-se em dividir este trabalho em três capítulos, sendo o primeiro destinado ao estudo da sociedade da informação, mostrando seu desenvolvimento.

No segundo capítulo, adentrou-se à temática da objetificação da mulher, a fim de possibilitar ao leitor a compreensão deste conceito.

Por fim, no terceito capítulo, o foco foi o estudo da objetificação, com vistas a responder o problema proposto, que é verificar sua relação com a sociedade da informação.

Para tanto, foi empregado o metodo indutivo de pesquisa e pesquisa bibliográfica.

\section{A SOCIEDADE DA INFORMAÇÃO}

Em pese todas as atrocidades cometidas durante a Segunda Guerra Mundial (1939 a 1945), é inegável que restaram algumas contribuições, a exemplo da criação de sistemas de informação, desenvolvidos pelos países que tinham como objetivo melhorar a sua defesa e tornar-se menos vulneráveis. Nesse sentido, Masuda (1982, p. 53) afirma que o primeiro estágio da sociedade da informação teve seu inicio em 1945, com o fim da guerra e durou até 1970.

Contudo, foi apartir na década de 70 que essas tecnologias se difundiram e passaram a tomar o mundo todo. A criação da internet, pelo Departamento de Defesa dos EUA, decorrente do desejo da existência de um sistema que não fosse vulnerável aos ataques nucleares, representou um dos mais importantes avanços tecnológicos.

O Japão foi um dos primeiros países a apresentar um plano de sociedade da informação, no ano de 1972, que foi dividido em duas etapas, uma denominada "Plano 
Intermediário de Impacto" e outra "Plano Básico de Longo Prazo". Depois do Japão vários países passaram a desenvolver sistemas de informação, a exemplo do Canadá que, em 1979, desenvolveu um sistema chamado Telidon; a Suécia que, em 1975 desenvolveu um sistema chamado Terese. (MASUDA, 1982, p. 19-41)

Até 1970 a base do sistema produtivo da sociedade era a mão-de-obra, considerada a principal ferramenta de trabalho disponível. No entanto, após a década de 70, o paradigma adotado passa a ser o da tecnologia da informação, que vai servir como base da chamada "sociedade da informação".

Esse novo paradigma apresenta algumas características peculiares, que são: a) a informação como matéria prima; b) penetrabilidade dessas novas tecnologias, que passam a moldar alguns processos da existência das pessoas; c) lógica das redes, que permitem que todos os sistemas organizacionais se adaptem facilmente; d) flexibilidade, que permite a reversão dos processos, bem como a sua modificação; e e) a grande capacidade de integração dos sistemas. (CASTELLS, 1999, p. 108-109)

É possível concluir que a sociedade da informação tem uma importante característica: substitui a sociedade industrial, marcada pela produção em massa, por uma sociedade intelectual, onde as pessoas tem a possibilidade de desenvolver sua criatividade o que, inevitavelmente, vai ocasionar mudanças na economia mundial. (MASUDA, 1982, p. 19)

Essas mudanças na economia são alavancadas, por dois fatores principais: a melhora na educação, em virtude de que, com o desenvolvimento intelectual das pessoas e o maior acesso à informação, a qualidade da educação também melhora; e o surgimento de novas oportunidades de trabalho, com foco na criatividade e na possibilidade de planejamento do futuro. (MASUDA, 1982, p. 85)

O modelo de produção adotado até 1970 era o de produção em massa, onde uma grande empresa possuía linhas de produção padronizadas. Entretanto, com a abertura do mercado mundial, aumentou a busca por produtos diversificados, o que tornou obsoleto o modo de produção que até então vinha sendo adotado. Assim, surgiu a necessidade de um sistema de produção que fosse flexível, capaz de atender as novas demandas, levando à superação do modelo tradicional de produção o que, inevitavelmente, demandou uma nova forma de organização das empresas, que tiveram que alterar a forma como vinham trabalhando. (CASTELLS, 1999, p. 212) 
Para Castells (1999, p. 209) a economia informacional que surge na sociedade da informação, nasce em contextos culturais muito distintos, isso pelo fato de que as influências de consumo são exercidas em todos os países do planeta, o que acaba criando "[...] uma estrutura de referências multiculturais".

A nova economia global que surgia demandava redução nos custos, aumento da competitividade e da produtividade, o que culminou na crise dos anos 70 , sobretudo pelo fato de que as pequenas empresas não conseguiram se adequar a essa nova estrutura organizacional alavancada pela sociedade da informação. (CASTELLS, 1999, p. 211)

Foi diante da crise do modo de produção que a lógica organizacional das empresas sofreu sensíveis alterações, que foram impulsionadas pelos avanços tecnológicos e que tinham como objetivo a automação do trabalho e a economia na produção. (CASTELLS, 1999, p. 210-211)

Diante das mudanças impulsionadas pela crise no modelo de produção ate então adotado, surge uma nova fase, agora focada no desenvolvimento da gestão empresarial, haja vista as alterações nos métodos de gerenciamento, que agora demandam mão-de-obra multifuncional e um rígido controle de qualidade dos produtos. Essa fase vai de 1955 a 1980.(CASTELLS, 1999, p. 214)

É nesse contexto que nasce o modelo gerencial denominado "Toyotismo", que surgiu no Japão e tem como características: o fim de estoques; controle rígido na qualidade; trabalho de produção em equipe; maior autonomia decisória aos trabalhadores; recompensa pelo bom desempenho das atividades e redução de incertezas. Enfim, é um modelo que se destaca pela troca de conhecimento e pela multifuncionalidade dos trabalhadores. (CASTELLS, 1999, p. 214-215)

O terceiro estágio, que se desenvolve entre 1970 e 1990, é chamado de "social", e preconiza a utilização da sociedade da informação para a resolução de problemas sociais, a exemplo da criação de sites pelo governo, com o intuito de poder angariar maiores informações sobre as necessidades da população e, até mesmo, a disponibilização de serviços pela internet.

O quatro estágio, que se inicia em 1975, busca atender as necessidades individuais dos usuários do sistema, o que é bem visível nos dias atuais, com a criação de redes sociais, sites para compra e venda de produtos, entre outros. (MASUDA, 1982, p. 55-56) 
O que se pode perceber é que a sociedade da informação teve sua gênese durante a Segunda Guerra Mundial, em razão da necessidade que os países tinham de avançar nas formas de proteção. A sua evolução passou por diversas fases, desde o seu desenvolvimento até chegar no atual estágio, onde o desenvolvimento está voltado para as demandas individuais.

A sociedade da informação está tão impregnada na vida das pessoas, que elas nem percebem isso, pois atividades como conversar pelo "Whatsapp", pagar contas pelo "internet banking", passaram a fazer parte da rotina.

Todo esse processo é facilitado pela convergência da base totalmente digital da sociedade da informação e pela velocidade em que as informações são difundidas, pois a internet se disseminou por, praticamente, todo o planeta.

\section{A OBJETIFICAÇÃO DA MULHER}

Para que seja possível compreender, ao final, a temática aqui proposta, é importante saber qual o significado do termo objetificação.

Segundo Nussbaum (1995) o conceito de objetificação geralmente é empregado como algo pejorativo, no sentido de que as mulheres deixam de ser vistas como um ser humano e passam a ser consideradas objeto sexual.

Esse tratamento conferido às mulheres, no sentido de considerá-las meros objetos sexuais, a disposição dos desejos masculinos, é, inclusive, um dos temas centrais das discussões feministas.

No entanto, Nussbaum (1995) afirma que o termo objetificação pode se apresentar com vários significados distintos, sendo eles bons ou ruins a depender do contexto em que é empregado.

Para explicar esses possíveis significados, a autora descreve várias cenas distintas para demonstrar que o termo objetificação, a depender do contexto em que é empregado, pode ter diferentes sentidos e, nem sempre, será considerado algo ruim. Algumas vezes a 
objetificação pode sim representar uma parte "maravilhosa" da vida sexual da mulher. (NUSSBAUM, 1995, p. 256)

A objetificação, em seu significado pejorativo, ocorre quando se nega às mulheres a sua condição de pessoa, e não quando objetos são tratados como tais. Ou seja, quando algo que não é objeto, é tratado como se o fosse, haverá a configuração da objetificação em seu sentido pejorativo.

(NUSSBAUM, 1995 ,

p. 257-258)

Na visão de Nussbaum (1995, p. 265), tratar um adulto como um fim em si mesmo é reconhecer a sua subjetividade e sua inviolabilidade, no entanto, tratá-lo como um mero instrumento para se chegar ao fim desejado é tornar o ser humano um objeto, especialmente porque, ao ser tratado como um objeto, o ser humano perde sua autonomia.

Entretanto, para saber, se de fato há objetificação, é imprescindível que seja analisado o contexto da situação, por exemplo, quando duas pessoas têm um desejo uma pela outra, isso não significa, necessariamente, que a relação que elas mantém é de objetificação, pois ao se relacionarem elas estarão, ao mesmo tempo, satisfazendo o seu parceiro e a si mesma. (NUSSBAUM, 1995, p. 276)

Por outro lado, nas situações em que uma pessoa utiliza outra para satisfazer seus próprios desejos em detrimento do outro, ou seja, quando não há reciprocidade de sentimentos, estará configurada a objetificação.

Um fenômeno mais recente, e que é uma decorrência da ideia de objetificação descrita por Nussbaum (1995), é o fenômeno da "auto-objetificação", que surge da tradução oriunda do termo inglês "self objetification", cuja teoria foi desenvolvida no intuito de demonstrar de que forma o apelo sexual ao corpo da mulher influencia na sua forma de viver e nas atitudes que adota. (FREDRICKSON; ROBERTS, 1997, P. 175)

Em que pese a questão referente à objetificação da mulher ainda não ser tão recorrente nas discussões que rondam os espaços públicos, isso em virtude de que a maior preocupação ainda reside na violência sexual contra as mulheres, o tema é atual e tem ganhado relevância. (FREDRICKSON; ROBERTS, 1997)

Apesar da pouca importância que é dada ao tema da objetificação, suas consequências são facilmente perceptíveis e, talvez, a principal delas é tornar a mulher um 
objeto sexual, alguém desejável aos olhos dos outros e também dela mesma, que passa a exigir de si um padrão estético. (FREDRICKSON; ROBERTS, 1997)

A objetificação pode se concretizar de várias formas, dentre elas, pela diminuição corporal, sexual, intelectual e laboral feminina, por meio de argumentos de fraquezas biológicas, dificuldade de acesso ao mercado de trabalho, diferença salarial, incapacidade emocional ou psicológica adequada, por propagandas publicitárias degradantes, entre outros. (FREDRICKSON; ROBERTS, 1997)

Para ser aceitas, as mulheres são levadas a se adequar ao padrão corporal definido socialmente; ser donas de casa; e ter independência financeira com um trabalho que, muitas vezes, lhes paga menos do que um homem receberia pelo mesmo serviço, o que frustra as expectativas de qualquer pessoa, pois desconsidera se tratar de um ser humano. (FREDRICKSON; ROBERTS, 1997)

Schemes; Araujo; Ledur (2008) registram que os padrões estéticos surgiram, a partir da década de 60, com o processo da obscuridade para a visibilidade da mulher, em que o corpo feminino, além de se tornar desejado, foi utilizado como objeto nos veículos de comunicação, justamente com intuito de venda de produtos destinados tanto ao público feminino, quanto ao masculino. Todavia, o surgimento desses padrões norteou a construção corporal e o papel social das mulheres.

A partir do momento que os corpos das mulheres passam para o âmbito público elas perdem domínio sob suas formas, que passam a ser sugeridas pela mídia. Assim, o efeito é reverso, pois ao invés de adquirir independência, tornam-se prisioneiras dessa imposição social, já que os padrões são extremamente difíceis de ser alcançados. (SCHEMES; ARAUJO; LEDUR, 2008)

Foi, especialmente, a partir da década de 80 , que a busca pelo corpo perfeito tomou maior relevância, e fez surgir a preocupação com alimentação saudável e prática de exercícios, momento em o corpo feminino deixou de ser visto por sua perspectiva biológica e funcional, e passou a ser visto como um veículo. (SCHEMES; ARAUJO; LEDUR, 2008)

Nesse sentido, nota-se que o corpo, enquanto veículo, manifesta as preocupações e características sociais da época em que vivencia, atendendo às exigências do período e da sociedade da qual faz parte. (SCHEMES; ARAUJO; LEDUR, 2008)

Não é difícil perceber a importância do papel das mídias nesse contexto, uma vez que, basta assistir filmes, seriados, novelas, comerciais, shows, entre outros, para se perceber 
que, na maioria da vezes, há um apelo muito forte ao corpo feminino, à forma como a mulher se veste, ficando seu talento relegado a um segundo plano. (FREDRICKSON; ROBERTS, 1997)

O mais interessante desse fenômeno é que ele se proliferou de tal forma na sociedade ocidental, que atinge mulheres de todas as classes econômicas, todos os graus de escolaridade, sem que as pessoas se deem conta disso. Ou seja, é algo extremamente comum e não chama atenção, pelo contrário, aquela mulher que não se encaixa nos padrões estabelecidos, é que passa a ser alvo de críticas. (FREDRICKSON; ROBERTS, 1997)

Essa imposição de um padrão da mulher ideal, desejável, causa consequências que vão muito além da aparência. É no plano psicológico que os efeitos recaem mais fortemente.

É o estado psicológico das mulheres que sofre com essa massiva objetificação, principalmente porque as pressões externas que são exercidas sobre elas fazem com que a sua aparência tenha uma importância extrema, o que desencadeia consequências negativas, tais como redução no nível de escolaridade, acesso a cargos de trabalho inferiores, dificuldades em encontrar um parceiro. (FREDRICKSON; ROBERTS, 1997)

Tentar se encaixar nos padrões sociais é uma tarefa árdua para as mulheres, mas ficar totalmente fora deles também é uma condição nada agradável, porque as mulheres que não se encaixam num padrão de beleza são, de certa forma, oprimidas pela sociedade, que lhe oferece menos chances. Para elas, as oportunidades são reduzidas, enquanto que aquelas que tem uma aparência que condiz com os padrões, tem maiores chances de ascender, seja na vida acadêmica, no trabalho ou nas relações amorosas.

Algumas das principais consequências psicológicas decorrentes da objetificação da mulher são elencadas por Fredrickson; Roberts (1997) e são elas vergonha, ansiedade, alterações de humor e a ideia de que a exposição do seu corpo pode ser uma forma de se impor socialmente.

Outra consequência tão extrema quanto a psicológica é a possibilidade que se abre para os abusos sexuais contra a mulher, uma vez que ela passa a ser tratada como um mero objeto e, em virtude disso, alguns passam a entender que podem fazer com seu corpo aquilo que desejarem. (FREDRICKSON; ROBERTS, 1997)

Um exemplo que tomou uma dimensão mundial foi o caso da menina indiana que foi brutalmente estuprada dento de um ônibus após sair do cinema com um amigo. Os seis 
estupradores afirmavam de forma veemente que a culpa era toda da menina, já que uma mulher que estava na rua àquela hora da noite (em torno das 22:00 horas), estava provocando os homens que, portanto, poderiam fazer com ela o que bem entendessem.

A objetificação da mulher, de certa forma, também contribui para o aumento de disfunções sexuais, ao ponto de influenciar na realização sexual das mulheres que tendem a ser infelizes sexualmente quando não tem confiança na sua aparência. São fatores que impedem o real alcance da equidade. (FREDRICKSON; ROBERTS, 1997)

Há outro dado que decorre da influência dessa ideia de objetificação e que infuencia nos hábitos alimentares das mulheres. Chegou-se ao numero assustador de $90 \%$ das mulheres ter enfrentado, ao longo da sua vida, bulimia e anorexia, chegando ao ponto de que se pode dizer que algumas mulheres sofrem de dieta crônica ou apresentam o problema, pois passam as suas vidas toda com restrições alimentares para garantir a sua boa aparência. (FREDRICKSON; ROBERTS, 1997)

Outra questão, não menos relevante, que deve ser considerada é que ao longo de sua vida, a mulher passa por diversas fases que representam intensas mudanças no seu corpo e isso tem uma influência direta na objetificação de seu corpo.

Observa-se que, pelo fato de o corpo ser utilizado cada vez com mais frequência pela mídia, essa exposição demasiada acaba por causar mudanças também nos padrões culturais.

Nesse sentido, o chamado "sexo frágil" acaba por se "auto-objetificar" para superar os danos de autoestima e adentrar à vida "normal".

Quanto mais nova a mulher, maior a imposição de que ela se encaixa nos padrões desejáveis, por isso, o período em que se verifica a maior influencia da objetificação vai da adolescência, mais ou menos aos treze anos de idade, até a meia idade, quando atinge cerca de cinquenta anos de idade. . (FREDRICKSON; ROBERTS, 1997)

Curiosamente, é a partir do momento em que a mulher deixa de ser vista como objeto sexual que, de certa forma, se liberta desses padrões e passa a ser reconhecida pelas suas habilidades e ter maior qualidade de vida, pois deixa de ficar vítima dos padrões culturais e tem mais condições de desenvolver sua autodeterminação. (FREDRICKSON; ROBERTS, 1997) 


\section{A SOCIEDADE DA INFORMAÇÃO SEUS REFLEXOS NA OBJETIFICAÇÃO DA MULHER}

O embrião daquilo que hoje se convencionou chamar de sociedade da informação, surge em razão da busca de maior segurança aos países que participaram da Segunda Guerra e se desenvolve, ao ponto de chegar à fase da internet, onde o desenvolvimento de sistemas permite que as informações sejam compartilhadas em tempo real, independentemente do local onde as pessoas se encontrem.

Entretanto, ao mesmo tempo que a internet favorece o compartilhamento de informações, ela também propicia uma exposição excessiva da intimidade das pessoas, bem como o controle sobre seus atos, pois ninguém tem certeza daquilo que é feito com os dados que circulam pela internet, a exemplo da publicação de informações sigilosas, como aconteceu no caso do "wikileaks". (MARTEL, 2015)

Outro fator importante que colabora para essa difusão do acesso à internet é o fato de que, grande parte do número de pessoas que tem acesso, o fazem por meio de celulares que, em geral, são mais baratos do que computadores e mais fáceis de ser transportados. (MARTEL, 2015)

Em alguns países, a exemplo do México, as empresas de telefonia adotaram, durante certo período, políticas de marketing em que não são cobrados os aparelhos de telefone celular e, em contrapartida, com um maior número de pessoas com celular, maior o consumo de planos de telefonia e mais vultuosos os lucros das empresas. (MARTEL, 2015)

Tais estratégias de marketing tem uma estreita ligação com o tema ora proposto, pois, considerando que os celulares, por mais simples que sejam, vem com uma câmera fotográfica acoplada, permitem que as pessoas fotografem todos os momentos de sua vida, o que não era possível quando haviam apenas câmeras fotográficas, pois dificilmente uma pessoa saia de casa levando consigo a câmera, enquanto que, dificilmente, alguém sai sem carregar consigo seu celular.

Os celulares, cada vez mais tecnológicos e com câmeras de alta resolução, aliados ao acesso à internet e à adesão às redes sociais, tornam o cenário perfeito para a publicação de fotos pessoais. 
É recorrente nas redes sociais a publicação de "selfies", que são aquelas fotos que a pessoa tira de si mesma, trata com algum programa para melhorar a imagem (na maioria das vezes) e publica para que seus "seguidores" curtam e teçam comentários.

A ampla difusão de selfies (fotos de si mesma) nas redes sociais, tem contribuído muito para a auto-objetificação, pois a própria mulher, captura imagem e faz sua edição, alterando, consideravelmente, sua aparência para que fique totalmente adequada aos padrões sociais de beleza. Depois de adequar sua aparência na foto, a mulher a publica para que outras pessoas possam vê-la e tecer comentários, elevando, assim, a sua autoestima. (KITIE; KITIE, 2014)

$\mathrm{Na}$ maioria das vezes essas imagens publicadas não condizem com a forma como a mulher é na realidade, mas perante aos outros, ela passa uma ideia de perfeição. (KITIE; KITIE, 2014)

É possível perceber, inclusive, um movimento de algumas mulheres famosas que se recusam a posar para revistas sob a justificativa de que não querem que a sua imagem seja transformada ao ponto de não se reconhecer na matéria estampada, contudo, esses movimentos são de pequena relevância, pois são isolados e sua repercussão não dura tempo suficiente para que essas discussões sejam lançadas de forma mais efetiva no espaço público.

O que poucas pessoas se dão conta é que esse massivo tratamento de fotos e imagens para alcançar uma perfeição poderá ter até uma consequência para o futuro, já que os retratos que são guardados não correspondem à realidade das pessoas, sendo que daqui há alguns anos, ninguém mais se reconhecerá nas imagens e os seus descendentes não saberão como seus antecedentes realmente aparentavam ser no passado, pois terão imagens totalmente divorciadas da real feição das pessoas no momento em que foram tiradas.

Essas situações, por mais que muitas vezes passem como despercebidas de tão presentes que estão no dia-a-dia, trazem consigo consequências danosas para o âmbito feminino, que sofre com esteriotipações em suas mais variadas formas.

Pensando na publicidade como fator primário (ou, pelo menos, um dos) da criação de padrões, esse conceito irradia (ou espalha) para outros campos da vida. Por isso que, muitas mulheres, influenciadas pelos padrões que frequentemente veem na mídia, acabam se "autopromovendo" por meio de publicações em suas redes sociais, distanciando-se, cada vez mais, da realidade e personalidade que as forma, rendendo-se a um mundo de futilidades. 
O que as mulheres precisam considerar é que não precisam adquirir um conceito de comportamento ou do que é um corpo. Essas são coisas que não podem ser consumidas, são aspectos muito particulares e é de crucial importância que as mulheres sejam educadas para reconhecerem seu valor e aceitar suas diferenças.

É lógico que a mídia contribui positivamente em muitos fatores de transformação, mas, sobretudo, é necessário saber selecionar as informações que são válidas e ignorar o que busca afetar a identidade e frustrar mulheres que, guiadas por protótipos, se deprimem, consomem seus tempos e seus corpos.

Ramos (2004, p. 156) questiona se é necessário mesmo uniformizar os corpos, afinal, alerta que a moda e o padrão corporal servem como meio de obtenção de lucro pelas grandes indústrias de vestuário, pois a produção em grande escala com preços padronizados só contribui para reforçar o capitalismo. Além disso, observa que "é na beleza, no padrão estético, que as diferenciações são ainda maiores - e mais sofridas também. O padrão estético e usado como forma de dominação".

Estabelecer esse padrão é mais lucrativo, porque além do setor vestuário, há o campo farmacêutico e alimentício que lucram com a venda de remédios, shakes e dietas baseadas e alimentos orgânicos e funcionais, o campo dos profissionais de educação física, fisioterapia, entre outros, que movimentam o capitalismo e fazem da objetificação do corpo feminino uma fonte lucrativa e de dominação.

Muitas vezes, para terem um destino diferente da submissão patriarcal e possuir independência financeira fácil e rápida, algumas mulheres optam por se prostituir.

Pateman (1993, p. 282), quando trata da prostituição, por exemplo, narra que, na opinião dos contratualistas, os que se opõem à prática alegando que a "prostituta é desonrada ou degradada" não entendem o que é oferecido e a natureza do negócio, sendo que não se trata de sujeição das mulheres aos homens, pois o que é oferecido não é seu corpo e seu ser, mas, sim, seus serviços. O autor explica, ainda, que o equívoco da prostituição é ignorar o problema da subordinação das mulheres e permitir sua exploração, comparando às explorações que sofrem os trabalhadores no sistema capitalista. Sendo assim, "em vez de as prostitutas serem encaradas como trabalhadoras exploradas, supõe-se que os trabalhadores estejam nessa mesma situação". 
Objetificar ou diminuir a mulher não torna sua luta perdida, mas faz com que o caminho seja de mais batalhas. Assim, cabe às mulheres ter consciência de sua posição como ser humano, igual em direitos e deveres.

Com base em toda pesquisa realizada, é possível perceber que o desenvolvimento da sociedade da informação, principalmente em seu quarto estágio, que se consagrou com o desenvolvimento das redes sociais, é um fator de extrema relevância para o tema da objetificação, pois aí se encontra um terreno fértil para a publicação de imagens que propagam a uniformização dos corpos, a criação de padrões ideias de beleza, alimentação, modo de se vestir entre outros.

\section{CONCLUSÃO}

O presente trabalho foi desenvolvido em três partes, sendo a primeira delas destinada a demonstrar o desenvolvimento da sociedade da informação, que surgiu como uma forma de garantir maior defesa aos países aliados na Segunda Guerra Mundial e passou por quatro estágios, que atualmente coexistem, sendo eles: desenvolvimento da internet pelo departamento de defesa dos EUA; alteração do modo de produção; resolução de problemas sociais e; mecanismos destinados a atender necessidades individuais dos usuários.

Já, no segundo capitulo, abordou-se a teoria da objetificação, desenvolvida no intuito de demonstrar de que forma o apelo sexual ao corpo da mulher influencia na sua forma de viver e nas atitudes que adota, o que acaba condicionando as mulheres aos padrões impostos pela sociedade para torna-las socialmente aceitáveis.

Por fim, chegou-se à analise da objetificação e de sua relação com a sociedade da informação.

Ao longo do desenvolvimento deste trabalho foi possível perceber que a sociedade da informação e a ideia de objetificação da mulher tem uma ligação muito estreita, especialmente pelo fato de que, após o desenvolvimento das mídias sociais, a publicação de fotos pessoais, impulsionou a criação de padrões estéticos socialmente aceitáveis. 


\section{REFERÊNCIAS}

Castells, M. (1999). A Sociedade em Rede. Volume I. $8^{\text {a }}$ edição revista e ampliada. São Paulo: Paz e Terra, 1999.

FREDRICKSON, Barbara L; ROBERTS, Tommi Ann. Objetification theory: toward understanding women's lived experiences and mental health risks. 1997. Disponivel em: http://www.sanchezlab.com/pdfs/FredricksonRoberts.pdf. Acesso em: 05 de junho de 2016.

KITE, Lexie Join; KITE, Lindsay. Runing from selfie-objetifications. 2014. Disponível em: http://www.beautyredefined.net/running-from-self-objectification/. Acesso em: 05 de junho de 2016.

NUSSBAUM, Martha C. Objectification. Philosophy and Publlic Affairs; Fall 1995; 24,4; Research Library Core, p. 249-291. Disponível em:

http://www.mit.edu/ shaslang/mprg/nussbaumO.pdf. Acesso em: 02/08/2016.

MARTEL, Friederich; Smart: o que você não sabe sobre a internet. Trad. Clóvis Marques 1 ed. Rio de Janeiro: Civilização Brasileira, 2015.

MASUDA. Yoneji. A sociedade da informação. Trad. Kival Charles Weber e Angela Melim. Rio de Janeiro: Ed. Rio, 1992.

PATEMAN, Carole. O Contrato Sexual. Tradução Marta Avancini. Rio de Janeiro: Paz e Terra, 1993.

SCHEMES, Claudia; ARAUJO, Denise Castilhos de; LEDUR, Cíntia. Corpo feminino: do anonimato à superexposição, anúncios publicitários do jornal NH. 2008. Disponível em: http://www.ufrgs.br/alcar/encontros-nacionais-1/encontros-nacionais/6o-encontro-20081/Corpo\%20feminino.pdf. Acesso em: 05 de junho de 2016. 